\title{
Implementation of 5S in Manufacturing Industry: A Case of Foreign Workers in Melaka
}

\author{
San Chee Houa ${ }^{1}$, M. Haslinda ${ }^{1}$, Sedek Muliati ${ }^{2}$, Abdullah Mariam Miri ${ }^{1}$, A. F. Rahim ${ }^{1}$ \\ ${ }^{1}$ Faculty of Technology Management and Technopreneurship, Universiti Teknikal Malaysia Melaka, 76100 Durian Tunggal \\ Melaka, Malaysia \\ ${ }^{2}$ Centre of Technopreneurship Development (C-TeD), Universiti Teknikal Malaysia Melaka, 76100 Durian Tunggal Melaka, \\ Malaysia
}

\begin{abstract}
Lean manufacturing system has been infiltrated in manufacturing sectors across the world. In fact, Lean manufacturing system is a practice which regards the use of the resources, creation of value for the end customers, and as the ways to eliminate the waste. There are several tools that can be used to eliminate the waste within the industry. This research is a study of the implementation of $5 \mathrm{~S}$ in manufacturing industry. Despite this, the research study focused on manufacturing industry, which has been implemented 5S system in Melaka State. Although there are number of tools and technique available to help in improving the manufacturing process, however, there is only few industries could implement the tools successfully. In this research, foreign workers play a main role in implement the $5 \mathrm{~S}$ systems as the manufacturing industry in Malaysia adopt large amount of foreign workers to work as employees. Therefore, it is important to ensure the foreign workers truly understand the concept of $5 \mathrm{~S}$ system and adopt the best ways to implement it in order to have better performance. This research study has been proposed by the research model of the barriers to implementation of $5 \mathrm{~S}$ in manufacturing industry among foreign workers. A several research method has been adopted to do the research, such as descriptive research design with quantitative methods, survey questionnaire and cross-sectional studies.
\end{abstract}

\section{Introduction}

According to N. Nordin et. al. [1] , the ultimate goal of a lean system is to create a smooth and high quality manufacturing that is able to produce finished products based on the customers demand without producing any waste during the operations. Lean thinking represents a set of principles and techniques for the identification and elimination of waste in manufacturing and administrative processes [2]. However, many industries in reality are not able to transform themselves to a lean manufacturing organization towards creating the world-class companies [3]-[5]. Due to that, Lack of knowledge is one of the most important problems of managers about familiarity with a convenient method to successfully improve the performance of the organization [6]. Furthermore, in this competitive environment, organizations have to make the best judgment and choose the best methods to achieve their target and not to lose very finite opportunities [7]. This is due to less effectiveness of implementing the $5 \mathrm{~S}$ systems into the workplace.

Through 5S methodology, the management can create an environment where quality work is comfortable, clean and safe in the organization and it can ensure the compliance to standards and will further foster continuous improvement [8], [9]. 5S is a system that used to reduce unwanted waste and optimize productivity through continuously maintaining the system in the workplace in order to consistent the operational results. The $5 \mathrm{~S}$ method is a tool for continuous improving lean management processes, where the task is to create a highly efficient, clean, and ergonomic working environment [10]. However, effort and participation from top management is a key factor that determines the success of the $5 \mathrm{~S}$ practice [11]. Moreover, most important barrier for implementation of $5 \mathrm{~S}$ effectively is poor communication and existing barrier between managerial level and shop floor employees and the poor training and awareness of $5 \mathrm{~S}$ [12].

$5 \mathrm{~S}$ systems is similar as the quote "A place for everything, and everything in its place" by Benjamin Franklin which state out that the best solution is keep things in their correct positions to avoid from the waste or unwanted actions.

Before the industry starts to implement new manufacturing process, the top management should identify the true meaning of $5 \mathrm{~S}$, why and how to implement $5 \mathrm{~S}$ system so that it will give beneficial for the industry. This report is concerned on the implementation of $5 \mathrm{~S}$ in manufacturing industries with the performance of foreign workers which located in

* Corresponding author: haslindamusa@utem.edu.my 
Melaka. All members within the industry, from the top management to the operator, should work together to have a better performance in implementing $5 \mathrm{~S}$ system and create the situation as one of the competitive advantages for the industry.

\section{S System}

Seiri (Sort) refers to the practice of going through all materials, tools, machines, etc., in the work area, identifying needs and unneeded items from them and keeping only the essential/needed items. When Sort is implemented in the workplace, the work area will be more apparent, and leading to a highly efficient workflow, at the same time the workers will be more satisfied with their environment Employee morale would increase as junk items or materials that are potential health hazards are identified and removed [2]. In 5S, it means removing from the shop floor where the items that the workers do not use routinely [13].

Seiton (Set-in-Order) deals with organizing the items that are needed in a way that best supports the employees doing the work. Is it the second step after implemented "Sort" [14]. Place things in such a way that they can be easily reached whenever they are needed. Set is the way to make the items look neat and reduce the time for searching the tools [15]. Set in Order focus on setting all the items in the industry into a certain place where the workers can simply find them. Manufacturing industry usually has many different tools and items, and that is the reason to set in order plays an important step to help the personnel save time to gather the items they need [16].

Seiso (Shine) step includes activities like cleaning workplace, maintaining its appearance and using preventive steps to keep the workplace clean [14]. Cleaning must be done not just after working shift, but apply on a regular schedule to remove dirt and dust from the workplace [17]. In other word, it is a way to notice problems early and to keep work areas and equipment in good operating condition even more to extend the duration. According to K. Marley and P. Ward [10], the idea for this stage is to have production operators clean their own workplaces at shift end, so that they notice details like spills, frayed cables, or broken lamps instead of just making the items become shine and bright.

Seiketsu (Standardization) is to create best practices and to get each team member to establish best practices the same way. According to S.S. Naqvi [18], this step focuses on identifying the best process in order to sustain the improvements and also continue to bring further improvements. Keeping standardization in industry workplace will helps in increasing the safety and meanwhile, reduction of the industrial pollution [2]. Standardization is the way to keep the first three $\mathrm{S}$, and make it as a standard method. Standardization also brings three $\mathrm{S}$ into regular work duties.

Shutsuke (Sustain/Self Discipline) for every worker and manager has to follow the procedures in the work place and workshop with utmost sense of discipline and sincerity in following the principles and procedures.
Sustain/Self Discipline is the final step in the entire $5 \mathrm{~S}$ system, but also is the hardest step for $5 \mathrm{~S}$. The Sustain step is the most difficult because it requires continued diligence. M. Suarez and J. Ramis [19] explained that if $5 \mathrm{~S}$ implementation failed in the middle way, it was due to the company never completed $5 \mathrm{~S}$ implementation. On the other hand, if the organization implements $5 \mathrm{~S}$ completely, a 5S program will have longevity [14].

The Framework of Employees' Motivation

N. Lukman et al., [20] have developed a theoretical model of employees' motivation I implementation of $5 \mathrm{~S}$ System. The proposed model will help to understand the factors that contribute to the success of $5 \mathrm{~S}$ implementation. In this framework, there are four independent variables that influence employees' motivation in implementing 5S System, organizational culture, management support, employee involvement and training. The results of the study revealed that organizational culture for $5 \mathrm{~S}$, management role for $5 \mathrm{~S}$ and training for $5 \mathrm{~S}$ have a significant relationship with employee motivation but insignificant for the employee involvement for $5 \mathrm{~S}$.

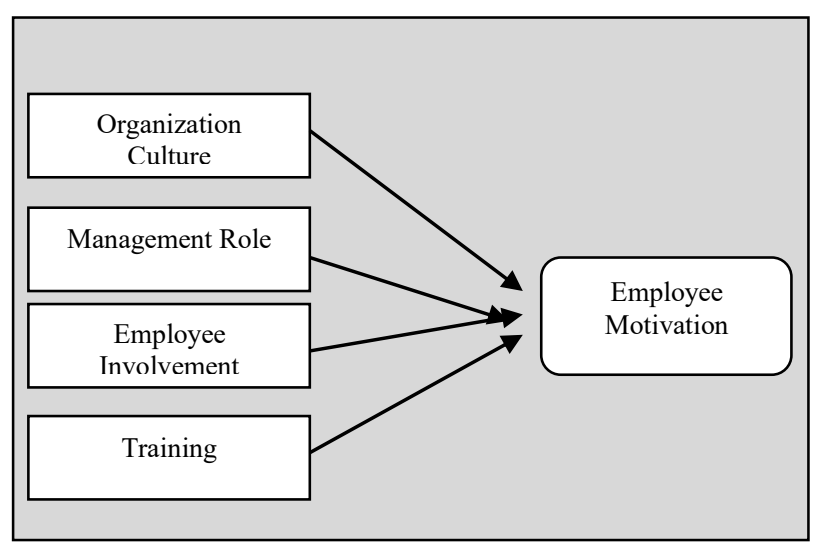

Fig. 1. The relationship of implementation of $5 \mathrm{~S}$ and employee motivation

\section{Methodologies}

Hence, this $5 \mathrm{~S}$ system will be used for improving the performance in manufacturing. There are several factors that will affect the successful implementation of $5 \mathrm{~S}$ among foreign workers as shown in Figure 2.

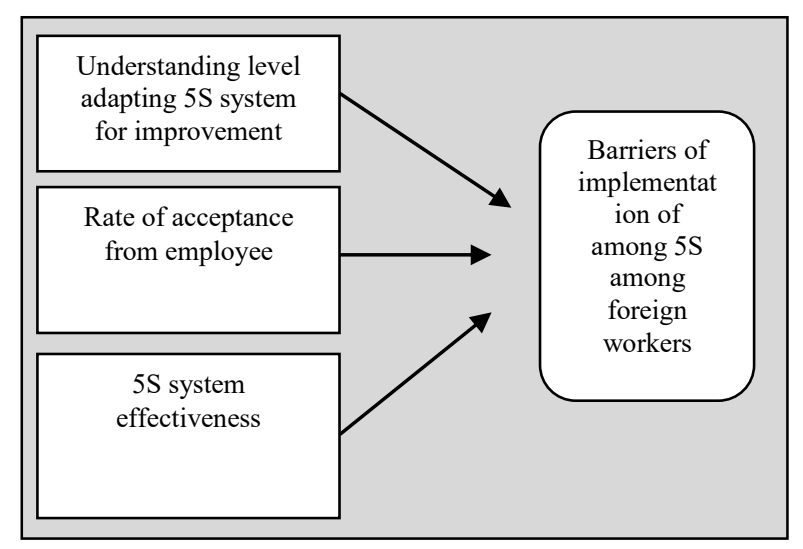

Figure 2. The conceptual model of implementation of 5S system 
Pilot studies will be needed to refine and improve in order to allow the respondents understand fully when answering to the question before distribute the questionnaire respondents in manufacturing industry. According to J. Check and R. Schutt [21], as before the final form of the questionnaire is conducted, it is recommended that conduct a pilot study in order to determine if the items are yielding the kind of information that is needed so as to give advance warning regarding weaknesses in a proposed study.

According to Saunders et al. [22], it is advisable to distribute the pilot test to the friends or family instead of unknown persons. The reason to conduct the pilot test is it provides the researcher the ideas for refine the questions and these friends and family are more likely to explain more the weakness of the questions that conducted. It is recommended that pilot test will be conducted to pre-test the questionnaire about 20 respondents. Hence, the response collected will be beneficial to improve the questionnaire before conduct the questionnaire to the respondents.

Once the respondents answered the questionnaire, a questionnaire will be collected and will analyze by using Statistical Package for the Social Science (SPSS) software. This software is used to conduct the analysis of descriptive statistics for describing and summarizing the data includes the measure of central tendency (average), ANOVA (analysis of variance) and dispersion ( the spread of data on how close each other is to measure of central tendency). The results will be shown by using SPSS, which in the form of descriptive statistics, reliability analysis, regression and Pearson correlation.

\section{Results and Discussion}

Most of the respondents were coming from Nepal, which 80 respondents out of 150 respondents. This was followed by $14 \%$ (21 respondents) are coming from Bangladesh, 11.3\% (17 respondents) from Indonesia, and $10.7 \%$ (16 respondents) from India. There were minority respondents which came from the Philippines and Pakistan, with 6.7\% (10 respondents) and 2.7\% (4 respondents), respectively. Last but not least, $1.3 \%$ (2 respondents) are coming from others countries.

Inferential analysis is concerned with making prediction or inferences from the sample data about the population might think, and it is used to make judgments about the probability that an observed difference between groups is a dependable one or one that might have happened by chance in the research.

Table 1 showed a correlation between independent variables and a dependent variable. These independent variables have a positive relationship with successful implementation of $5 \mathrm{~S}$ among foreign workers. This means that if there is an increase in understanding level adapting $5 \mathrm{~S}$ systems for improvement, rate of acceptance from employees or $5 \mathrm{~S}$ system effectiveness, it will also improve the successful implementation of $5 \mathrm{~S}$ among foreign workers.
Table 1. Correlation

\begin{tabular}{|c|c|c|c|c|}
\hline & 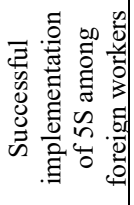 & 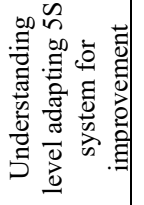 & 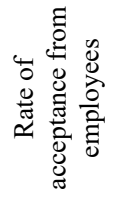 & 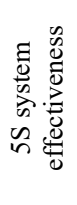 \\
\hline 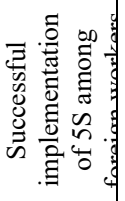 & 1 & & & \\
\hline 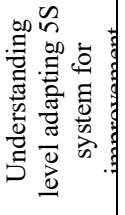 & $.557 * *$ & 1 & & \\
\hline 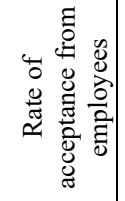 & $.516^{* *}$ & $.503 * *$ & 1 & \\
\hline 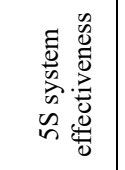 & $.525 * *$ & $.559 * *$ & $.589 * *$ & 1 \\
\hline
\end{tabular}

Table 2 showed a model summary of multiple regression analysis. The $\mathrm{R}$ values between independent variables were in positive number, 0.639 , which meant it was a good relationship between the independent variable and dependent variable. $\mathrm{R}$ square showed that the three independent variables influenced the successful implementation of $5 \mathrm{~S}$ among foreign workers was equal to 0.409 which meant that $40.9 \%$ of the variables influenced the dependent variables. However, 59.1\% $(100 \%-40.9 \%)$ was influenced by other factors which were not discussed in this study.

Table 2. Regression Analysis of the relation between independent variable and dependent variable

\begin{tabular}{|c|c|c|c|c|c|}
\hline Model & $\mathbf{R}$ & $\mathbf{R}^{\mathbf{2}}$ & $\begin{array}{c}\text { Adjuste } \\
\mathbf{d ~ R}^{\mathbf{2}}\end{array}$ & $\begin{array}{c}\text { Error of } \\
\text { the } \\
\text { Estimate }\end{array}$ & Sig. \\
\hline 1 & 0.658 & 0.409 & 0.397 & 0.231 & 0.00 \\
\hline
\end{tabular}

Table 3 showed the highest significant value for independent variable is the $5 \mathrm{~S}$ system effectiveness, which shown as 0.016 significant value. The 
unstandardized coefficient (B) is the partial regression coefficients as the values were taken into account the other predictor variables in the model and they will perform the predicted change in the dependent variable for every unit increase in the predictor. Understanding level has a significant positive influence on the successful $5 \mathrm{~S}$ implementation among foreign workers, which has the strongest impact $(t=4.102, p=0.000, \beta=$ 0.323 ). Rate of acceptance from employees has a significant positive influence on the successful $5 \mathrm{~S}$ implementation among foreign workers where $(t=2.815$, $p=0.006, \beta=0.184)$. $5 \mathrm{~S}$ system effectiveness has a significant positive influence on the successful $5 \mathrm{~S}$ implementation among foreign workers where $(t=2.438$, $p=0.016, \beta=0.190$ ).

Table 3. Regression Analysis on Coefficients

\begin{tabular}{|c|c|c|c|c|c|}
\hline \multirow{2}{*}{ Model } & \multicolumn{2}{|c|}{$\begin{array}{c}\text { Unstandardized } \\
\text { Coefficients }\end{array}$} & \multirow[b]{2}{*}{ Beta } & \multirow{2}{*}{$t$} & \multirow{2}{*}{ Sig. } \\
\hline & B & $\begin{array}{c}\text { Std. } \\
\text { Error }\end{array}$ & & & \\
\hline 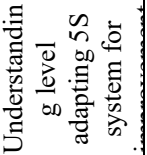 & 0.323 & 0.079 & 0.329 & 4.102 & 0.000 \\
\hline 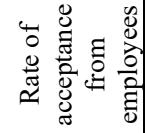 & 0.184 & 0.065 & 0.230 & 2.845 & 0.000 \\
\hline 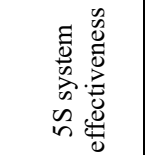 & 0.190 & 0.078 & 0.207 & 2.815 & 0.006 \\
\hline 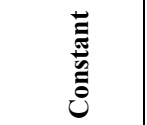 & 1.349 & 0.313 & & 4.315 & 0.00 \\
\hline
\end{tabular}

The coefficient for the understanding level was 0.323. It meant that the understanding level was increasing 0.323 was predicted while other variables were set as constant. It also happen the same with another two variables which were rate of acceptance from employees and $5 \mathrm{~S}$ system effectiveness. The coefficient for the rate of acceptance from employees was 0.184 . It meant that the rate of acceptance from employees was increased to 0.184 was predicted while other variables were set as constant. Lastly, the coefficient for the $5 \mathrm{~S}$ system effectiveness was 0.190 . It meant that the $5 \mathrm{~S}$ system effectiveness was increased to 0.190 was predicted while other variables were set as constant.

\section{Conclusion}

In conclusion, this study had been discussed on concluding the data analysis of the previous chapter, providing suggestion to overcome and improve the lean implementation and proposing recommendation for future study. The research question has been constructed and it had been determined and concluded by the result of data analysis, and finally answered the research objectives of this study.

\section{References}

1. N. Nordin, B. Deros, and D. Wahab, "A survey on lean manufacturing implementation in Malaysian automotive industry," Int. J. Innov. Manag. Technol., vol. 1, no. 4, 2010.

2. V. Patel and H. Thakkar, "A Case Study: 5s Implementation in Ceramics Manufacturing Company," Bonfring Int. J. Ind. Eng. Manag. Sci., vol. 4, no. 3, pp. 132-139, 2014.

3. I. Rajiani, H. Musa, and B. Hardjono, "Ability, Motivation and Opportunity as Determinants of Green Human Resources Management Innovation," Res. J. Bus. Manag., vol. 10, no. 1, pp. 51-57, 2016.

4. H. Musa, N. A. Rahim, F. R. Azmi, A. S. Shibghatullah, and N. A. Othman, "Social Media Marketing and Online Small and Medium Enterprises Performance: Perspective of Malaysian Small and Medium Enterprises," Int. Rev. Manag. Mark., vol. 6, no. 7S, pp. 1-5, 2016.

5. N. Nordin, B. M. Deros, D. A. Wahab, and M. N. A. Rahman, "A framework for organisational change management in lean manufacturing implementation," Int. J. Serv. Oper. Manag., vol. 12, no. 1, p. 101, 2012.

6. P. Rai, "Effectiveness of 5S Implementation on Organizations Performance," Abhinav Int. Mon. Ref. J. Res. Manag. Technol., vol. 5, no. 1, pp. 1-10, 2016.

7. S. R. Bin Ashraf, M. M. Rashid, and A. R. M. H. Rashid, "Implementation of 5S Methodology in the Small Scale Industry: a Case Study," Int. J. Sci. Technol. Res., vol. 4, no. 3, pp. 1791-1796, 2017.

8. S. Sorooshian, M. Salimi, S. Bavani, and H. Aminattaheri, "Case report: Experience of $5 \mathrm{~S}$ implementation," J. Appl. Sci. Res., vol. 8, no. 7, pp. 3855-3859, 2012.

9. S. Kanamori, S. Sow, M. C. Castro, R. Matsuno, A. Tsuru, and M. Jimba, "Implementation of $5 \mathrm{~S}$ management method for lean healthcare at a health center in Senegal: A qualitative study of staff perception," Glob. Health Action, vol. 8, no. 1, pp. 1-9, 2015.

10. K. A. Marley and P. T. Ward, "Lean management as a countermeasure for 'Normal' disruptions," Oper. Manag. Res., vol. 6, no. 1-2, pp. 44-52, 2013.

11. M. N. A. Rahman, N. K. Khamis, R. M. Zain, B. M. Deros, and W. H. W. Mahmood, "Implementation of $5 \mathrm{~S}$ practices in the manufacturing companies: A case study," Am. J. 
Appl. Sci., vol. 7, no. 8, pp. 1182-1189, 2010.

12. A. Ghodrati and N. Zulkifli, "A Review on $5 \mathrm{~S}$ Implementation in Industrial and Business Organizations," J. Bus. Manag., vol. 5, no. 3, pp. 11-13, 2012.

13. M. Malmbrandt and P. Åhlström, "An instrument for assessing lean service adoption," Int. J. Oper. Prod. Manag., vol. 33, no. 9, pp. 1131-1165, Aug. 2013.

14. R. S. Agrahari, P. A. Dangle, and K. V Chandratre, "Implementation of 5S Methodology in the Small Scale Industry: a Case Study," Int. J. Adv. Res. Innov., vol. 3, no. 1, pp. 130-137, 2015.

15. A. Jain, R. Bhatti, and H. Singh, "Productivity Improvement Through 5S Implementation in Indian Manufacturing Industries," in Productivity Improvement Through 5S Implementation in Indian Manufacturing Industries, Springer, New Delhi, 2014, pp. 535545.

16. C. HungLin, " $5 \mathrm{~S}$ implementation in Wan Cheng Industry Manufacturing Factory in Taiwan," University of Wisconsin-Stout, 2011.
17. S. Gupta and S. K. Jain, "An application of $5 \mathrm{~S}$ concept to organize the workplace at a scientific instruments manufacturing company," Int. J. Lean Six Sigma, vol. 6, no. 1, pp. 73-88, Mar. 2015.

18. S. S. Naqvi, "Towards Successful Implementation of 5Ss in a U.S. Manufacturing Company with Indian SubContinent Workers," Eastern Michigan University, 2013.

19. M. F. Suárez-Barraza and J. Ramis-Pujol, "An exploratory study of 5S: a multiple case study of multinational organizations in Mexico," Asian J. Qual., vol. 13, no. 1, pp. 77-99, Jun. 2012.

20. N. Lukman, W. A. Aziz, and A. H. Zakaria, "The relationship of implementation of $5 \mathrm{~S}$ and employee motivation," in conferences or management of higher education.

21. J. Check and R. Schutt, Research methods in education. Sage Publications, 2011.

22. M. Saunders, Research methods for business students, 5/e, 5th ed. Pearson Education India, 2011. 